\title{
A doença também cura: a doença como fonte de autêntica vida humana na obra literária de Fernando Namora
}

\section{The disease also cures: the disease as a source of authentic human life in the literary work of Fernando Namora}

\section{FERNANDO TEIXEIRA BATISTA*}

Resumo: A partir dos livros Retalhos da vida de um médico, O homem disfarçado e Domingo à tarde, do escritor português Fernando Namora, nos quais os protagonistas são médicos, refletimos sobre: ficcionalização da atividade clínica; interseção dos conhecimentos individuais do doente e universais da doença (convocando o conceito lukácsiano de particularidade); significados e preconceitos que à doença se poderão associar (pessoal e socialmente); estados psicológicos e emocionais dos doentes e dos médicos (partindo nestes da confissão e autoanálise); anamnese e interação médicopaciente; contributo da enfermidade para a queda das máscaras dos que com ela têm de lidar, pacientes e clínicos.

Palavras-chave: Fernando Namora, literatura, medicina narrativa, doença

\begin{abstract}
From the books Retalhos da vida de um médico, $O$ homem disfarçado and Domingo à tarde, from the Portuguese writer Fernando Namora, in which the protagonists are doctors, we reflect on: the fictionalization of clinical activity; the intersection of the patient's individual knowledge and the universal knowledge of the disease (summoning the lukácsian concept of particularity); meanings and assignable prejudice to the disease (personal and social); psychological and emotional states of patients and doctors (taking as a starting point confession and self-analysis); anamnesis and doctor-patient interaction; how the disease may contribute to the fall of the masks of those who have to deal with it, both patients and clinicians.
\end{abstract}

Keywords: Fernando Namora, literature, narrative medicine, disease.

\footnotetext{
Licenciado em Humanidades Clássicas pela Faculdade de Filosofia da Universidade Católica Portuguesa. Mestre em Supervisão Pedagógica em Ensino do Português, pela Universidade do Minho, com dissertação sobre a leitura de poesia na escola. Doutor em Literaturas e Culturas Românicas, na especialidade de Literatura Portuguesa, pela Faculdade de Letras da Universidade do Porto, com tese sobre a obra literária de Fernando Namora.
} 
e aceitarmos que a introspeção e a incursão nos meandros do ser humano podem potenciar o conhecimento do homem, poderemos aceitar também que, se este não soubesse o que era o sofrimento, a narrativa literária sobre a condição humana não seria mais que literatura infantil. ${ }^{1}$ Nesse sentido, poderemos também concordar com Eduardo Lourenço, para quem a plena saúde é "pouco propícia à efabulação", sobretudo a uma efabulação que mergulhe na complexa profundidade humana - o que, todavia, acontecerá também com a "pura doença", como reconhece o mesmo ensaísta (Lourenço, 2000, p. 11).

Poder-se-á concordar, também, que o contacto próximo com o sofrimento do homem em situações-limite potencia a reflexão sobre a condição humana, bem como a interiorização do sofrimento alheio, a solidariedade com o infortúnio e a única experiência possível da morte, a dos outros. Desse modo, poderá reconhecer-se que - em natural proximidade com o sofrimento e com a doença, "o lado sombrio da vida" (Sontag, 1998, p. 11), bem como com a morte - o médico-escritor que deseja auscultar a alma humana e confessar-se perante um espelho, em jeito de autoscopia, poderá tocar o mais fundo e verdadeiro da alma humana, para mais facilmente poder aceder aos recônditos meandros do homem que se escondem nas relações sociais e que emergem com o desespero.

É, pois, de reconhecer que literatura e medicina se poderão, por vezes, sobrepor; esse "território partilhado", recorrendo a palavras do médico e escritor Moacyr Scliar (apud Santana Júnior, 2012, p. 205), torna-se decerto mais visível quando o escritor torna-se médico ou o médico se faz escritor. Essa interseção, que potenciará a cultura do homem na sua totalidade, foi um traço distintivo da vida e da obra do escritor português Fernando Namora, escritor-médico que ficcionalizou a profissão clínica, bem como o universo da doença e seus fantasmas fazendo daquela uma "reserva de emoções literárias". (Lourenço, 2000, p. 21). A doença, para além dos seus limites biológicos, assume também sentidos psicossomático-sociais. Na realidade, as problemáticas social e existencial coabitam na alma perscrutada dos protagonistas dos romances namorianos, resultando

\footnotetext{
1 Recordamos López Ibor, que escreve no prefácio de Deuses e demónios da medicina de Fernando Namora: "El sufrimiento es el gran fuego avivador de la creación literária. Si la humanidad no hubiera sufrido tanto no habría salido de los cuentos infantiles; porque la literatura no es solo imaginación, sino comprensión y excursión por las entrañas dislaceradas del hombre". (Ibor,1989, p. 13).
} 
num realismo humano que sintetiza neorrealismo e existencialismo, tendências literárias às quais o escritor mais frequentemente é associado.

Aceitando que a literatura capta as ideias de uma sociedade sobre a saúde, a doença e a medicina, reconhecemos que, em Namora - numa escrita de confissão e catarse, possibilitada pela imersão na profundidade da alma humana autêntica dos seus doentes (sem máscaras em situação-limite) e pelo confronto do médico e do intelectual com a doença e a sociedade -, encontram-se diagnósticos de todo o tipo de defeitos e enfermidades (conquanto a sua escrita seja tendencialmente resistente a visões metafóricas da doença, ainda que não totalmente expurgada delas), paralelamente ao desnudar da alma dorida que o autor tão bem conhecia, a sua. No fundo, em Namora, o confronto do médico com o caos dos corpos é tão significativo como o confronto do escritor com o caos do mundo.

O escritor ficcionaliza, pois, a atividade do médico - em formas de consulta ao domicílio, no interior de Portugal, em Retalhos da vida de um médico, e no ambiente hospitalar da capital, em $O$ homem disfarçado e Domingo à tarde - recriando os bastidores da doença. É sobre essas obras que falaremos aqui.

Em Retalhos da vida de um médico (1949), a pobreza e a ignorância, observadas nos momentos trágicos da doença humana, são expostas cruamente e, de alguma forma, relacionadas com a realidade social de desigualdades e padecimentos vários do Portugal rural da sua época. Tornam-se visíveis as ideias daquela sociedade rústica sobre a doença e a ação médica. Encontramos populares cujas crendices os levam a colocar peles de animais sobre os lençóis, durante o parto, e mulheres que justificam imperfeições de recém-nascidos com a eventual passagem de um anel sobre a barriga da mãe. Encontram-se preconceitos sobre algumas doenças: lê-se na obra: "Na vila, não se podia falar em tuberculose. (...) Falar dessa doença era falar de lepra. Fraqueza de pulmões, bronquite, por exemplo, já eram designações suportáveis". (Namora, 1989, p.181). Veem-se, também, atuações negligentes e perigosas de curandeiros, barbeiros ou comadres.

Na realidade, essas narrativas, bem como os romances que se seguem, vão-se construindo no confronto entre o desejo do autor de contribuir para a redução do sofrimento dos homens e da sua consciência de impotência perante a fragilidade da condição humana e a desordem e a iniquidade do mundo. Essa impotência percebe-se em O homem disfarçado (1957): "Todos acabamos por ser 
triturados por uma engrenagem absorvente, desumana. Quem detém as rédeas desta caranguejola já não somos nós, mas sim a vida que criámos". (Namora, 1988, p.141). Talvez, por isso, a doença oncológica de Clarisse de Domingo à tarde (1961) - que nos faz pensar na sociedade líquida contemporânea, a qual não pode ser mudada retirando-lhe um elemento que esteja a corrompê-la - seja a leucemia, "a forma branca (...) de cancro, que não pode ser tratada com nenhum tipo de cirurgia mutilante". (Sontag, 1998, p. 26).

Ainda que a ficcionalização da atividade clínica possa interessar particularmente aos médicos, nomeadamente por as obras potenciarem a compreensão dos doentes e das suas narrativas, na verdade, o contributo para o conhecimento do homem torna esse tipo de obras literárias, como essas de Fernando Namora, interessantes a todos os leitores. ${ }^{2}$

Nas narrativas de Retalhos, a partir de consultas aos doentes da aldeia, vê-se a família como o lugar privilegiado da tragédia. É no seu espaço, quase sempre miserável, que a morte ceifa as infelizes vidas. Predominam, por isso, nessas narrativas, sobretudo relações individuais, entre o médico e o doente. Aceitando, precisamente, que a prática médica é fundamentalmente uma relação entre pessoas, Moacyr Scliar reconhece, também, que a tecnologia é necessária, todavia ressalva: "o que precisamos é fazer com que a tecnologia não desloque o relacionamento entre seres humanos porque, afinal de contas, a prática médica é fundamentalmente isso, uma relação entre pessoas" (apud Santana Júnior, 2012, p. 225). Em Retalhos, essa relação, sendo próxima, torna-se uma relação empática: o médico deseja chamar a si o sofrimento do doente e "reagir com alma contra a doença, numa espionagem infatigável que não permitisse o assalto traiçoeiro da morte" (Namora, 1989, p. 63). A doença é vista pelo mé-

\footnotetext{
2 Sobre a potencialidade dessas narrativas, escreve Rita Charon: "Medicine can benefit from learning that which literary scholars and psychologists and anthropologists and storytellers have known for some time - that is, what narratives are, how they are built, how they convey their knowledge about the world, what happens when stories are told and listened to, how narratives organize life, and how they let those who live life recognize what it means. Using narrative knowledge enables a person understand the plight of another by participating in his or her story with complex skills of imagination, interpretation, and recognition. With such knowledge, we enter others narrative worlds and accept them - at least provisionally - as true. (...) Narrative medicine can help answer many of the urgent charges against medical practice and training - its impersonality, its fragmentation, its coldness, its self-interestedness, its lack of social conscience". (Charon,2006, p. 9-10).
} 
dico como o inimigo: "Eu queria lutar com desespero contra a doença, chamá-la a mim, vigiá-la infatigavelmente; reanimar de vida esse corpo vencido. Mais soro, mais tónicos, tudo o que havia à mão. Foram horas de febre, às vezes de desalento, outras de esperança, ao lado do inimigo que se apoderava irresistivelmente duma vida" (op. cit. p. 59). A entrega à luta contra a doença abeira-se do desespero: "Precisava de persistir. E entreguei-me a cada doente que me procurava com um ardor desesperado. Dias e noites, a horas escusas, faminto de êxito e simpatia, ia rondar o sofrimento, animar os impacientes, oferecer-me inteiro à vida alheia". (op. cit. p. 82). Parece doer-lhe a dor dos que lhes pedem auxílio. O escritor João José Cochofel, coetâneo e amigo de Namora, destaca, precisamente, a humanidade percetível no tom confessional destas narrativas:

uma das mais curiosas facetas desse livro consiste quanto a nós precisamente no seu tom tão desnudamente confessional, na humildade com que Fernando Namora se olha e surpreende sentimentos contraditórios, erros e remorsos, nascidos das próprias determinantes que regem as circunstâncias em que a vida e a das suas personagens se encontram e entrelaçam. A inexperiência do jovem acabado de sair da faculdade; os míseros escudos que recebe daquela pobre gente e lhe queimam as mãos; o sentimento de culpa perante o reconhecimento da sua inutilidade, do seu comodismo ou dos seus caprichos; a tenacidade, as lutas, as alegrias e os triunfos; a compaixão, o enternecimento e a revolta cruzam-se para imprimir uma profunda humanidade a Retalhos da Vida de Um Médico. (Cochofel, 1950, p. 115-116).

$\mathrm{Na}$ atuação clínica, a anamnese do doente é, frequentemente, o ponto de partida para o médico fazer o diagnóstico. Nesse sentido, são necessárias predisposição e experiência para o clínico interagir verbalmente com o paciente; confessa o médico de Domingo à tarde a propósito da história clínica de um doente: "Apreendi toda essa história violentando-lhe os monossílabos". (Namora,1993, p.31). Por vezes, os sintomas descritos pelos doentes são muito vagos e em termos pouco precisos: Lê-se em Retalhos: "O homem (...) avisara-me de que se tratava de uma dor. E na vila falava-se de uma dor como de um prenúncio de enterro". (Namora, 1989, p. 137). Verifica-se, também, certa tendência para a negação da doença, referindo-se os doentes ou os familiares a doenças menos graves, procurando levar o clínico para longe das suas suspeitas; na narrativa 
"Tuberculose", diz a mãe da doente ao médico: "Tem trazido a garganta inflamada, parece que os escarros se pegam às goelas. E ela, de tanto tossir, puxou o sangue". (op. cit. p.183). Outras vezes, pelo contrário, as queixas são exageradas; afirma o médico de Retalhos: "O doente pobre sente que precisa de justificar plenamente, perante a família, a sua queixa, a sua invalidez, ou a despesa que se vai fazer, e daí exagerar até ao inverosímil os seus incómodos". (op. cit. p. 107).

Não será, no entanto, possível que o médico, partindo decerto dos sintomas no doente e da anamnese clínica, não convoque o seu conhecimento sobre a doença, entendida esta como linguagem universal. ${ }^{3}$ É no doente que o médico diagnostica a doença, procurando, naturalmente, pelo conhecimento desta e pelos sintomas naquele, perceber-lhe as causas e adequar tratamentos, se os houver. Também o escritor Fernando Namora apresenta o homem singular e a Humanidade, o indivíduo e a sociedade, o local e o mundo, a parte e o todo; no fundo, o tipo e a particularidade que Lukács defendia esteticamente. (Namora, 1978, p.176).

O olhar clínico do médico de Retalhos está constantemente presente potenciando a verbalização de quadros clínicos por um léxico próprio; recordemos algumas passagens: um doente é apresentado com "olhos injectados, vermelhos de febre e rancor". (Namora, 1989, p. 106); sobre outra doente, diz o médico: "Ficou amuada. (...) Chorou todo o dia, a febre subiu, o coração parecia enlouquecido de encontro às costelas". (op. cit. p. 187); sobre a desilusão amorosa dessa paciente, lê-se a seguir: "aquilo acabou em novas hemoptises; e um halo esverdeado apareceu debaixo da pele transparente, rodeando os olhos meigos. Nunca mais sorriu" (op. cit. p.189). Sobre um parto complicado, conta o médico a determinado momento: "Via-se já a cabeça cianosada da criança, com vergões de sufocação". (op. cit. p.172).

Para além do olhar e da linguagem do clínico, percebe-se um olhar humano, sentindo-se uma vontade desesperada e uma forte empatia humanas. $\mathrm{O}$ médi-

3 Pierrette e Gérard Chalendar, estudiosos da obra de Namora, referem sobre o exercício da medicina: "A arte médica é, antes de tudo, uma semiologia: a partir de sintomas observados no indivíduo, como localização da dor, cumpre-lhe descobrir a natureza do mal. Também o comportamento social do enfermo esconde um conjunto de volições, de aspirações, dos quais nem sempre tem consciência nítida mas que nem por isso deixam de constituir a razão de ser da sua conduta" (Chalendar, 1979, p. 25). O próprio Fernando Namora recordou num outro livro: "etimologicamente, diagnóstico, fulcro do acto médico, sugere aptidão para compreender" (Namora,1990, p. 30). 
co, perante uma luta perdida para a doença, não rejeita o seu papel e envolve-se na procura de formas que pudessem suavizar a dor de doentes incuráveis. Nessas narrativas, como bem observa Mário Braga, "o médico é uma espécie de parceiro de Deus, na cura e na compaixão". (Braga, 1988, s/p). Sente-se, também, uma significativa dificuldade de anunciar a morte aos doentes e aos familiares: chega a esconder a verdade ao marido de uma doente e familiar sua (Namora, 1989, p. 39); reconhece noutra narrativa: "já não sabia se preferia ou não que o marido da doente adiasse o momento em que deveria confessar-lhe a sentença". (op. cit. p. 70).

A esperança do doente é compreendida e mesmo alimentada pelo médico, tanto como auxílio na tentativa de cura da doença - reconhece o clínico: "eu queria senti-la a vencer o desânimo, decidida, confiada. Era o melhor auxílio que ela me podia prestar". (op. cit. p.187) - como enquanto lenitivo para suavizar dores e desesperos que se desejam suportáveis. A esperança na cura improvável em situações dramáticas de doença não surge apenas associada à ignorância. Em Domingo à tarde, o médico relaciona desespero, fragilidade e esperança, contando um episódio protagonizado por outro clínico:

Uma ocasião aparecera-me aquele colega que, havia muito, conhecia como um profissional severo e honesto. Tinha um cancro. E sabia-o. Como pudera estranhar que ele, a meia voz, fungando muito, me falasse numas tisanas que a cozinheira Ihe recomendara? Tão frágeis são as pessoas quando a tragédia as fende de alto a baixo. (Namora,1993, p. 197).

Colocados, angustiantemente, perante a doença, os doentes e os próprios médicos que com eles lidam tendem a imergir para lá do superficial. De facto, em Namora, deparamo-nos com o fenômeno de autoscopia das figuras médicas, que tendem para a confissão. Para além de se encontrarem continuamente expostos ao julgamento pelas almas que a eles recorrem, frequentemente em angústia e rogando o alívio das suas dores físicas e psíquicas, eles mesmos se apresentam ao espelho e se interrogam dramaticamente. Eduardo Lourenço constata que é "no contacto com o magma dos seus sofrimentos humanos que os heróis, ou o autor-herói, das novelas, dos contos ou dos romances de Fernando Namora experimentam, com uma sensibilidade de esfolados vivos, a sua inegável fragilidade ontológica". (Lourenço, 2000, p. 12). O contacto com o 
sofrimento e o desespero da alma humana que se desnuda contribuiriam, sem dúvida, para a escrita confessional do escritor-médico Fernando Namora e levá-lo-iam a uma necessidade de libertação pela própria escrita. Em Retalhos da vida de um médico, os episódios narrados, a partir das consultas, resultam, pois, sobretudo em autoanálise e confessionalismo: "Namora quis falar dos outros, do mundo dos outros, e falou de si através deles". (Rodrigues, 1993, p.128). O médico precisa dessa catarse literária. A escrita torna-se o lugar onde o seu espírito se confessa, onde busca, solitariamente, tratamento e alívio para as feridas que sangram com os outros.

Em Retalhos, o tom confessional de certos casos de consciência é recorrente. Os biografemas das narrativas permitem-nos, desde logo, estabelecer "pactos autobiográficos", recorrendo a uma expressão de Philippe Lejeune (1975, p. 2931). Recordemos a frase inicial do livro: "Com vinte e quatro anos medrosos e um diploma de médico, tinha começado a minha vida em Monsanto". (Namora, 1989, p. 17). ${ }^{4}$ O narrador é um médico jovem, inseguro, por vezes com sentimentos de culpa quando a recuperação de algum doente não se verificava; muito vigiado pelo olhar desconfiado dos populares - "ali na aldeia (...), um médico (...) tem de salvar uma pessoa da família antes que conquiste a intimidade e a confiança de um lar". (op. cit. p. 77); em confronto constante com bruxas e curandeiros, sentindo-se por isso uma "espécie de feiticeiro medieval" (op. cit. p. 30); pouco credível aos olhos de alguns populares - "os médicos envenenam as pessoas", lê-se numa narrativa da 2a série de Retalhos (Namora, 2000, p. 64). Surge, também, em conflito interior, devido à consciência da sua "inutilidade de médico de aldeia, longe de tudo, sem laboratórios, sem remédios, salvando o que a morte despreza, remediando o que a natureza resolveria sozinha" (op. cit. p. 139).

Domingo à tarde é uma obra de cunho introspetivo que apresenta as experiências diárias de um "azedo e solitário" (Namora, 1993, p. 14) médico oncologista, no qual se sentem certas "vagas de misantropia" (op. cit. p.200), caracterizado por um "cepticismo agressivo" (op. cit. p.13) e descrente da eficácia dos recursos disponibilizados pela ciência da época para o tratamento de pessoas portadoras de cancro. O clínico é distante e pouco comunicativo; confessa o médico: "os diálogos com os doentes, em regra, exigiam-me pouco mais do que

4 Estes elementos correspondem, na realidade, à biografia do escritor Fernando Namora. 
resmungos e acenos breves de cabeça, a despachar...". (op. cit. p.68). As suas características surgem estreitamente associadas ao facto de pertencer à ala das doenças oncológicas do hospital as quais, nos pobres doentes, provocam uma "devoção aterrorizada (op. cit. p.55). O próprio justifica a autoimagem: "o horror dos meus ofícios se apossara da minha personalidade, desfigurando-a". (op. cit. p. 18). Só Clarisse, personagem do romance, será capaz de suavizar a dureza do médico e de transformar a sua atitude perante a doença, o sofrimento e a solidão, mostrando-Ihe a importância da solidariedade, da compreensão e da empatia humanas na fragilidade da doença, mesmo na ausência de recursos científicos viáveis. A confissão resulta, também, no reconhecimento da máscara que usa, que, no fundo, é uma estratégia para adquirir prestígio e liberdade dentro do hospital. Nuns momentos revela uma cruel indiferença para com os pacientes, noutros mostra compaixão: "por debaixo desta crosta enfatuada sangrava a minha tímida adesão aos dramas que me rodeavam" (op. cit. p. 36). No fundo, o que o médico-narrador deseja é "desnudar a magra verdade que se escondeu por detrás do (...) amor-próprio". (Namora,1993. p 15).

Em $O$ homem disfarçado, o protagonista é um médico rico e reconhecido na cidade que se encontra amargurado, nauseado de si, das suas máscaras e da sua conivência com a degradação. Vítima e comparsa de uma sociedade que o ensinou a fingir, tenta, numa crise de consciência, procurar uma clareira onde, sem disfarces nem corrupções, possa encontrar um sentido para a vida e uma oportunidade de solidariedade humana. Restam-lhe apenas duas opções: ou permanece fiel aos seus princípios e à sua consciência e naufraga socialmente ou cede ao esquema e naufraga interiormente. (Coelho, 2007, p. 180).

Em qualquer dos livros, sente-se a necessidade de libertação pela escrita e deparamo-nos com confissão e busca de autoconhecimento. Reconhece o protagonista de $O$ homem disfarçado, quem se confessa que tem "como principal objectivo ver-se a si próprio com clareza, livrar-se de uma carga de simulações". (Namora, 1988, p. 218). De facto, como bem observa Eduardo Lourenço sobre Namora, "desta procura de si mesmo, o ofício de médico foi durante muito tempo a condição exterior e o universo do sofrimento humano a matéria inesgotável". (Lourenço,2000, p. 21).

A busca da verdade humana (tema central na obra do escritor), em contexto social invariavelmente mascarada, confronta a autenticidade gerada pela iminência da morte e o disfarce e a teatralização de que a saúde se reveste social- 
mente. ${ }^{5}$ O homem, constantemente vigiado pelo olhar do Outro, enquanto doente, passará a sobrevalorizar o seu olhar interno. A doença devolve o homem a si, à sua pureza, pondo cobro à mentira das relações sociais epidérmicas em que vivemos. Perante o desespero da "morte marcada por um despertador que, uma vez que Ihe foi dada corda, ninguém o fará parar". (Namora, 1993, p. 149), o doente deixa de competir com o mundo e passa a ter o contendor dentro de si, o inferno é ele próprio.

É na narrativa "O cão", de Retalhos da vida de um médico, que o escritor apresenta a mais excelente alegoria da verdade e autenticidade humanas. Jorge, um adolescente doente e revoltado com o seu estado, procura, frequentemente, um refúgio ou uma arma para se defender do contacto com os outros. Possui um cão grande e feroz. Quando fala do Tejo, o seu cão, era como se falasse de si. Diz-nos o narrador: "o que nele (em Jorge) era autêntico, audaz, vital, e ninguém lhe subjugaria, estava ali, a dois passos, obediente ao seu chamado, uma força bruta da natureza que ele domava como senhor". (Namora, 2000, p. 245). O médico-narrador, que também tem um cão, confronta o adolescente com a possibilidade de soltar o cão sem que este morda alguém; diz-lhe: "o meu cão é forte sem deixar de ser manso. (...) é dócil e meigo sem ser cobarde". (op. cit. p.246-247). O rapaz sentiu-se melindrado e "o cão, quando viu ou sentiu o Jorge um tanto... preocupado... pôs-se também a sangrar". (op. cit.: 248). A mãe do adolescente rebelde - o qual, para não ferir o outro, mandara prender o Tejo no quintal - deu ordens que o soltassem. Enquanto o rapaz, conhecendo a natureza e a raiva do seu cão, parecia, de alguma forma, temer que o seu Tejo, selvagem como um lobo, atacasse o narrador, este observa: "O animal quedou ainda uns momentos na pose de ir ou não esfacelar-me e, por fim, roncando, de raiva arrefecida, a baba a escorrer-Ihe fumegante, deitou-se aos pés do dono". (op. cit. p. 250). Em

\footnotetext{
5 São vários os estudiosos que concordam com a centralidade dessa temática na obra namoriana. Fernando Mendonça refere a "autenticidade humana" como a maior relevância literária do autor (Mendonça,1978, s/p); Eduardo Lourenço menciona o "sonho da autenticidade" como a aventura patética e reveladora da sua obra (Lourenço, 2000, p. 20); Matilde Rosa Araújo considera que é no homem verdadeiro e no homem disfarçado que reside a matriz conflitual da sua produção literária (1988: s/p). Nelly Novaes Coelho afirma que "é no âmbito dessa problemática - a da ausência de autenticidade, que faz malograr o verdadeiro convívio humano - que Namora desenvolve toda a sua diversificada obra" (2007, p. 178).
} 
toda essa narrativa parece estar presente a possibilidade de se viver, naturalmente, a simplicidade e a verdade humanas, sem que isso vitimize os outros. ${ }^{6}$

Clarisse, a jovem altiva e irreverente que é internada no hospital, de Domingo à tarde, depois de tomar consciência da sua leucemia, esquece o seu disfarce; diz o médico-narrador: "horas depois, quando entrei no laboratório, fui encontrá-la num banquinho baixo, quase aninhada, a fazer perguntas assustadoramente ingénuas à minha assistente". (Namora, 1993, p. 40). Noutra passagem, reconhece o médico sobre ela: "a doença e o desespero iam amachucando a soberba de classe". (op. cit. p. 53). Notará, ainda, noutro episódio: "o dinheiro não tinha, ou perdera para ela, todo o significado". (op. cit. p. 180). Ela própria confessa: "nada tenho dentro de mim a não ser o medo". (Namora, 1993, p. 121). Susan Sontag afirma, precisamente, que a morte do canceroso tende a ser retratada "como tendo-o roubado de todas as suas capacidade de se transcender, humiIhado pelo medo e pela agonia". (Sontag, 1998, p. 25). O reconhecimento de total ausência de poder e de entrega às mãos de outros poderá compreender-se na súplica da jovem Clarisse: "Não me deixes morrer". (Namora, 1993, p. 193). O fim das suas preocupações com a face social associar-se-á também a uma busca de viver intensa e autenticamente o momento presente. Riposta Clarisse aos lamentos de uns amigos que acabam de conhecer o seu estado doentio: "E que importa que eu tenha leucemia? Já é muito acordar de manhã e sentir-me viva. Conquista-se a vida todas as manhãs. É um gozo que vos está vedado". (op. cit. p. 191). De facto, na literatura como na vida, a iminência da morte gera momentos nos quais algo pode ser comunicado na sua autenticidade e são, sobretudo, esses os momentos que potenciam algumas reflexões sobre a tragédia da condição humana.

A autenticidade, sem disfarces, das personagens compreende-se também, frequentemente, pelo seu silêncio em diversos contextos, pois as palavras parecem mascarar a verdade e teatralizar as atitudes. ${ }^{7}$ De facto, o silêncio dos doen-

6 Sobre essa narrativa, reconhece João Gaspar Simões, crítico próximo do segundo modernismo português: "O Cão proporciona-nos uma oportunidade quase insuspeitada de ver esboçar-se, nas mãos, deste neo-realista, um retrato psicológico de um adolescente como outro não há, talvez, na galeria das criações adolescentes da ficção nacional". (Simões, 1981, p. 270).

7 Apesar de, na produção literária de Namora, ser no meio urbano que os constrangimentos do diálogo surgem mais evidentes, algumas personagens das narrativas rurais também se mostram parcas em palavras. Na narrativa "A visita", um camponês, informado pelo médico sobre o estado de saúde da sua esposa - "Ela vai morrer" -, apenas exteriorizou pausadamente: "Pois é. Uma 
tes, que mostra um mundo de aceitação e resignação que não busca máscaras, tem também significativa presença nesses livros. A comunicação, que tendencialmente diminui, torna-se mais sincera, intensa e sentida.

A tendência para o rasgar das máscaras - as quais malogram o convívio humano e a autêntica comunicação frustram o indivíduo, forçando-o à clandestinidade e à solidão - é característica das personagens doentes que têm consciência do seu estado grave ${ }^{8}$ mas é também uma busca dos médicos que se confessam, em confronto com a doença, nesses livros de Namora.

Embora a verdade humana que se impõe na doença grave não seja sempre elogiável - por vezes a maldade vem à superfície,$-{ }^{9}$ a doença tende a curar a enfermidade social de que o homem padece a constante proteção, valorização, hipertrofia da sua pele, em face do olhar alheio. Essa cura, devido à proximidade com o sofrimento, pode manifestar-se também nos clínicos, como parece querer acontecer nos processos de metamorfose dos médicos destes livros de Namora, nomeadamente pela adesão ao sofrimento alheio, à proximidade e à comunicação com os doentes. No romance Domingo à tarde, o médico tem consciência da máscara que veste e da sua insociabilidade, que, no fundo, é uma estratégia para adquirir prestígio e autonomia dentro do hospital. Os pobres doentes tendem a olhar para ele com devoção aterrorizada: "Eles forçavam-me tanto a ser cúmplice da sua ansiedade, ou viam-me tão responsável por ela, que acabavam em ter por mim uma devoção aterrorizada". (op. cit. p. 55). O romance apresenta, todavia, já uma possibilidade de novos horizontes. À significativa questão de Lúcia no

chatice" (Namora,1989, p. 73). Parece que as personagens consideram que as palavras as traem. Na narrativa "História de um parto", o pai da parturiente - um homem em quem se sentia uma dor humilde e silenciosa e se percebia prece nos olhos, receando o momento delicado da filha após o sucesso do parto, grato e emocionado, não conseguiu encontrar palavras para agradecer ao médico (op. cit. p. 23).

8 Em Estamos no Vento, uma narrativa literário-sociológica, Fernando Namora sustenta precisamente que "a medicina continua a não se bastar com os manuais, indo sempre mais dentro do homem para o entender na saúde e na doença, sabendo que esta, por lhe afrouxar as resistências, não raro desvenda o que até aí se dissimulara em disfarces". (Namora,1995, p. 207).

9 Recorde-se, a título de exemplo, na narrativa "A tuberculosa" de Retalhos da vida de um médico, a reação da doente quando ouve uma história de uma infeliz como ela: "tinha ouvido a história com um entusiasmo malvado" ( 1949, p. 191). Lembremos, também, a vingança da mãe da doente, dos comentários e do afastamento da vizinhança: "A Srạ Ermelinda não perdoou mais as vizinhas. E agora que as via afugentadas dos lavadoiros, do nojo da roupa da Maria Jacinta, atraía as crianças a casa e dava-lhes restos da doente (...). Era a sua vingança”. (op. cit. p. 187). 
final do romance - podemos começar? -, a resposta é: podemos (op. cit. p. 217). A rotina do médico, que "parece cuspir nas pessoas e confunde ternura com pieguice" (op. cit. p. 18), modifica-se ao conhecer Clarisse, uma paciente com a qual se envolve sentimentalmente e à qual busca realizar os desejos, até à sua morte inevitável. Ela será capaz de suavizar a dureza do médico e de transformar a sua atitude perante a doença, o sofrimento e a solidão, mostrando-Ihe a importância da solidariedade, da compreensão e da empatia humanas na fragilidade da doença, mesmo na ausência de recursos científicos viáveis.

Por fim, julgamos que para os próprios clínicos, de alguma forma, poderá ter também poder terapêutico a procura por parte desses - caracterizados por vezes por certa melancólica indiferença emocional -, através da escrita, do encontro com o seu refúgio solitário, com a criação ficcional, com a verdade, a confissão e a catarse.

\section{Referências}

ARAÚJO, Matilde Rosa. Aprendizado da vida perante a dor dos outros. In AAVV. Fernando Namora - 50 anos de vida literária. Estoril: Estoril Sol S. A. Galeria de Arte do Casino do Estoril, 1988.

BRAGA, Mário. Principal e tenaz inventor de uma nova maneira de estarmos no mundo. In AAVV. Fernando Namora - 50 anos de vida literária. Estoril: Estoril Sol S. A. Galeria de Arte do Casino do Estoril, 1988.

CHALENDAR, Pierrette \& Gérard. Temas e estruturas na obra de Fernando Namora. Lisboa: Moraes, 1979.

CHARON, Rita. Narrative medicine. New York: Oxford University Press, 2006.

COCHOFEL, João José. Retalhos da Vida de Um Médico por Fernando Namora. In Vértice, Coimbra, no 78, pp. 115-116, 1950.

COELHO, Nelly Novaes. Fernando Namora: romance-testemunho da contemporaneidade. In Escritores portugueses do século XX. Lisboa: INCM, 2007 pp. 173-188.

IBOR, López. Prefácio. In NAMORA, Fernando. Deuses e demónios da medicina. Mem-Martins: Europa-América, 1989.

LEJEUNE, Philippe. Le pacte autobiographique. Paris: Éditions du Seuil, 1975.

LOURENÇO, Eduardo. Prefácio - Escrita e doença na obra de Fernando Namora. In NAMORA, Fernando. Retalhos da vida de um médico - $2^{\underline{a}}$ série. Mem Martins: Europa-América, 2000. 
LUKÁCS, Georges. Introdução a uma estética marxista. Rio de Janeiro: Civilização Brasileira, 1978.

MENDONÇA, Fernando. Breve diagnose da obra de Fernando Namora. In Fernando Namora: 40 anos de vida literária. Amadora: Bertrand, 1978.

NAMORA, Fernando. O homem disfarçado. Mem Martins: Europa-América, 1988.

NAMORA, Fernando. Retalhos da vida de um médico - $1 \underline{a}$ série. Mem Martins: Europa-América, 1989.

NAMORA, Fernando. Prefácio. In NAMORA, Fernando. Casa da malta. Mem Martins: Europa-América, 1990.

NAMORA, Fernando. Domingo à tarde. Mem Martins: Europa-América, 1993.

NAMORA, Fernando. Estamos no vento. Mem Martins: Europa-América, 1995.

NAMORA, Fernando. Retalhos da vida de um médico - 2a série. Mem Martins: Europa-América, 2000.

RODRIGUES, Urbano Tavares. A horas e desoras. Lisboa: Edições Colibri, 1993.

SANTANA JÚNIOR, Fernando Oliveira. Medicina ética e judaísmo na literatura: da anamnese à narrativa do doente em A Majestade do Xingu, de Moacyr Scliar. In FERREIRA, Ermelinda Maria Araújo e NINO, Maria do Carmo (org.). Literatura e medicina. Recife: Editora Universitária, 2012, pp. 221-239.

SIMÕES, João Gaspar. Fernando Namora. in Crítica IV, Lisboa: INCM, pp. 267-277, 1981.

SONTAG, Susan. A doença como metáfora e a sida e as suas metáforas. Lisboa: Quetzal, 1998.

Submetido em: 05-11-2015

Aprovado para publicação: 01-07-2016 